\title{
Hydrocephalus complicating pituitary adenoma
}

\author{
H. A. SHENKIN AND J. N. CROWLEY \\ From the Department of Neurosurgery, Episcopal Hospital, \\ Philadelphia, Pennsylvania, U.S.A.
}

SUMMARY Hydrocephalus complicated the clinical course of four patients with pituitary adenoma. In three it was noted late, long after surgical intervention and radiotherapy had been carried out. In one patient, hydrocephalus was part of the presenting syndrome. The differential diagnosis of hypopituitarism and occult hydrocephalus is difficult. The possibility of hydrocephalus complicating a pituitary adenoma constitutes another indication for arteriography before carrying out definitive treatment, or should the clinical course be unsatisfactory at any time.

Hydrocephalus in adults as a complication of neurological entities, such as subarachnoid haemorrhage, has been increasingly remarked upon in recent years. Its occurrence even without increased intracranial pressure or a clearly understood aetiology has provided us with a new neurological syndrome, so-called occult or low pressure hydrocephalus. Undoubtedly, the availability of an effective treatment, the various shunting procedures utilizing a unidirectional valve, has spurred its recognition in these various circumstances.

The occasional occurrence of hydrocephalus in the presence of a pituitary tumour has been mentioned in the past (Pancoast et al., 1940; Davidoff and Epstein, 1955; Dandy, 1969). However, in the recent literature it has been alluded to only infrequently and only passing mention of its specific therapeutic implications has been made (Stern and Batzdorf, 1970). Four
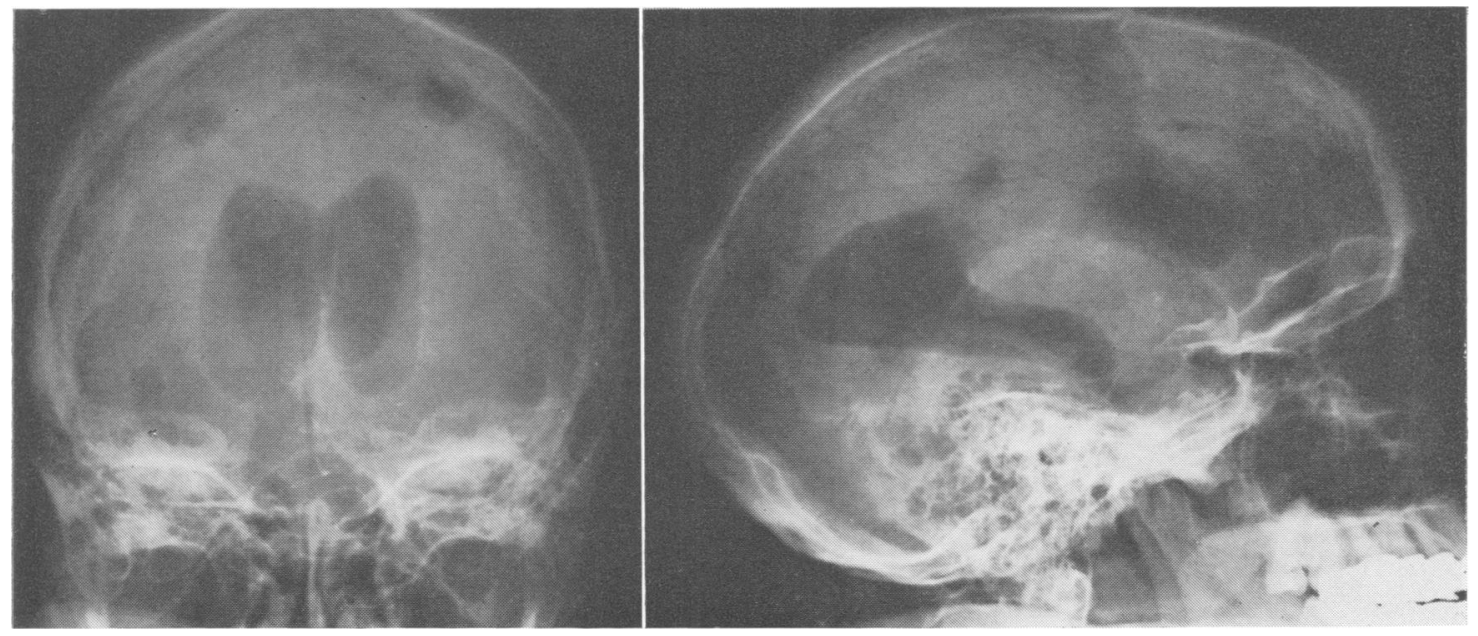

FIG. 1. Case 1 (J.K.) Ventriculogram. A-P and lateral views demonstrating enlarged ventricles and lack of visualization of third ventricle. Pericallosal angle is relatively acute $(A-P$ view $)$, further suggesting obstructive hydrocephalus. 
such patients have been encountered in the past seven years and are the subject of this report.

\section{CASE 1}

J.K., a 50 year old woman, was examined in 1956, with a progressive history of tiring easily and somnolence over a period of two months. She had a right homonymous hemianopia with normal visual acuity and a generally enlarged sella turcica with the anterior clinoid processes preserved and the dorsum destroyed. Her serum protein-bound iodine (PBI) was $6 \mathrm{mg} / 100 \mathrm{ml}$. and the 24 hour urinary 17 ketosteroid excretion was $24.4 \mathrm{mg}$. Ventriculography revealed no increase of intracranial pressure and normal ventricles except for some distortion of the left temporal horn. Exploration of the optic chiasm and beneath the left temporal lobe failed to disclose tumour. Radio therapy was given and 3,500 $r$ were delivered to the pituitary fossa and the region just posterior to it. The visual fields showed no improvement, but other symptoms remitted.

In 1963 she had a recurrence of complaints of tiring easily, somnolence, and forgetfulness. She was alert, oriented, and cooperative but had some unsteadiness of gait and a right homonymous hemianopia was again noted. Pneumoencephalography demonstrated moderately dilated lateral ventricles but the third ventricle was poorly visualized. The aqueduct and fourth ventricle were normal. PBI was $7 \cdot 1 \mathrm{mg} / 100 \mathrm{ml}$., 24 hour urinary corticosteroid excretion $8.3 \mathrm{mg}$, and 17-ketosteroid excretion $5 \cdot 1 \mathrm{mg}$. ACTH stimulation test was normal as was the metapyrone test. Because she was depressed, methylphenidate, $5 \mathrm{mg}$ t.i.d. was started, in addition to prednisone, $10 \mathrm{mg}$ daily.

She improved for a time and then began experiencing progressive difficulty with her gait and her memory became even poorer. In 1964 a second course of radiotherapy was administered, a tumour dose of 3,500 $r$ being delivered to the region of the sella turcica. Within two weeks she was considered to be brighter, with some improvement of gait and memory, but this improvement was not maintained and she was readmitted to the hospital in March 1964 with the added symptom of urinary incontinence. A Torkildsen's procedure was carried out and she became brighter and her memory improved.

Early in 1965 she began to have syncopal episodes and by April she was mentally obtunded, incontinent, and bedfast. Endocrine studies now showed no evidence of hypopituitarism. Ventriculography demonstrated lateral ventricles larger than noted in 1963 without visualization of the third ventricle os (Fig. 1). The Torkildsen's shunt was functioning, as $\vec{a}$ demonstrated by injecting dye into a lateral ventricles 용 and recovering it in the lumbar sac. A right trans frontal craniotomy was performed and biopsy of $工$ necrotic tissue from the sella turcica was reported to be compatible with chromophobe adenoma. Thir ventriculostomy was performed. She did not improve and was discharged to a nursing home.

In September 1965 she was seen again because of sudden onset of right hemiplegia and aphasia?

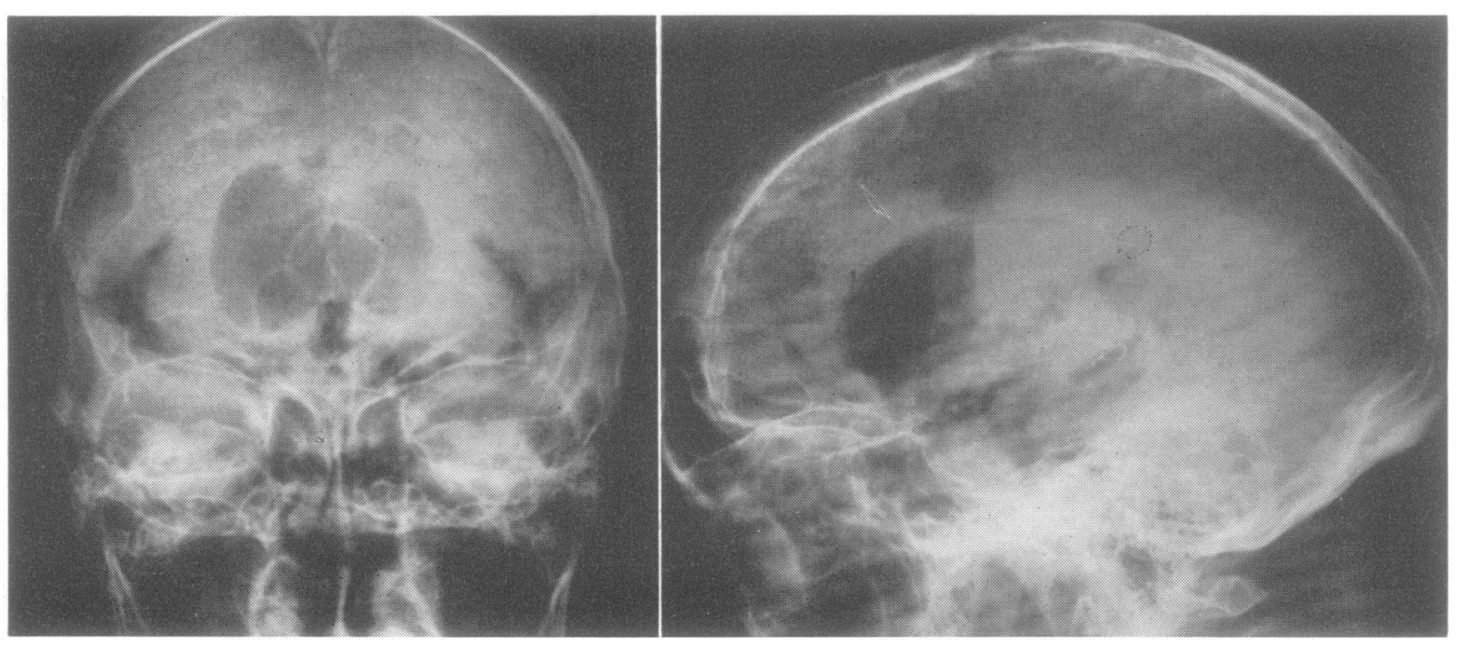

FIG. 2. Case 2 (P.B.) Pneumoencephalogram. A-P and lateral views showing dilated lateral ventricles. 

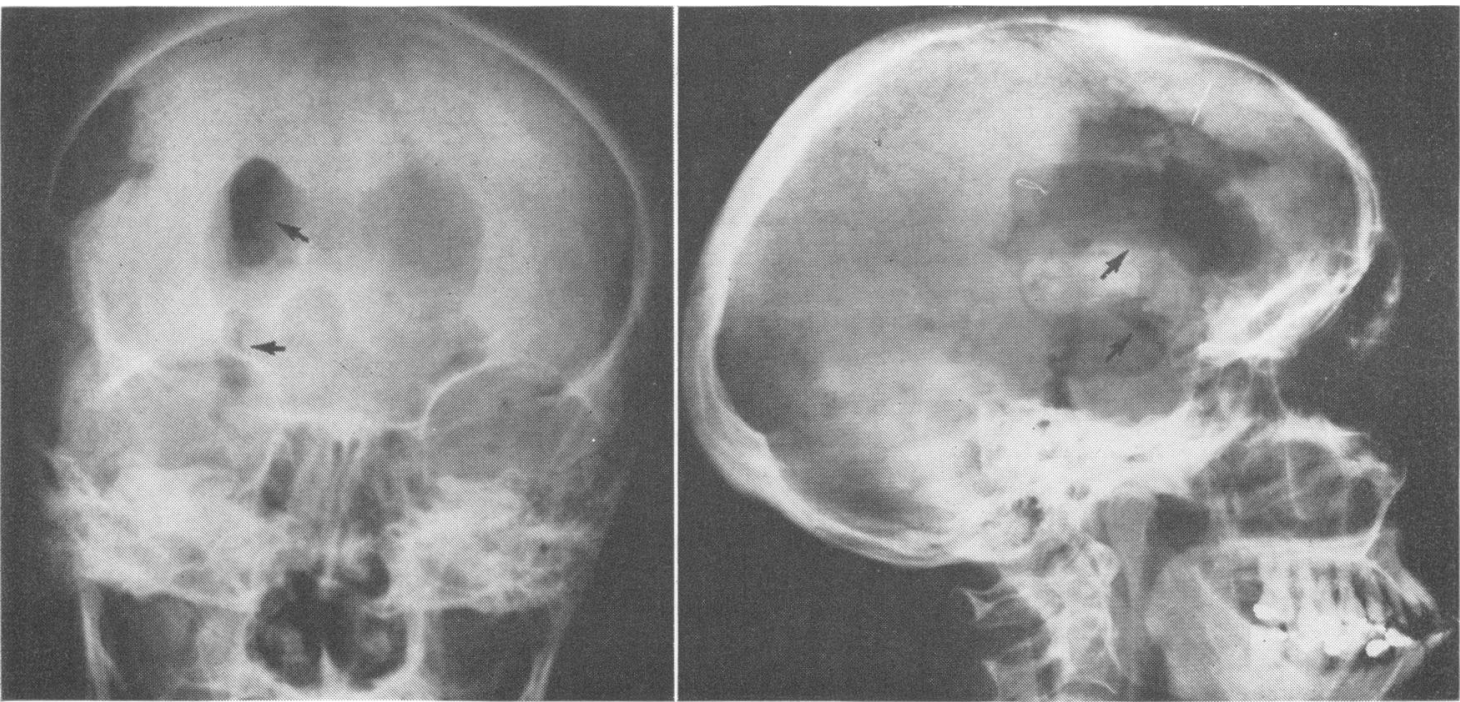

FIG. 3. Case 3(M.K.) Pneumoencephalogram. A-P and lateral views showing dilated lateral ventricles and huge suprasellar extension of pituitary tumour (lower arrows in each view). Upper arrows point out extension of tumours to area of foramen of Monro.
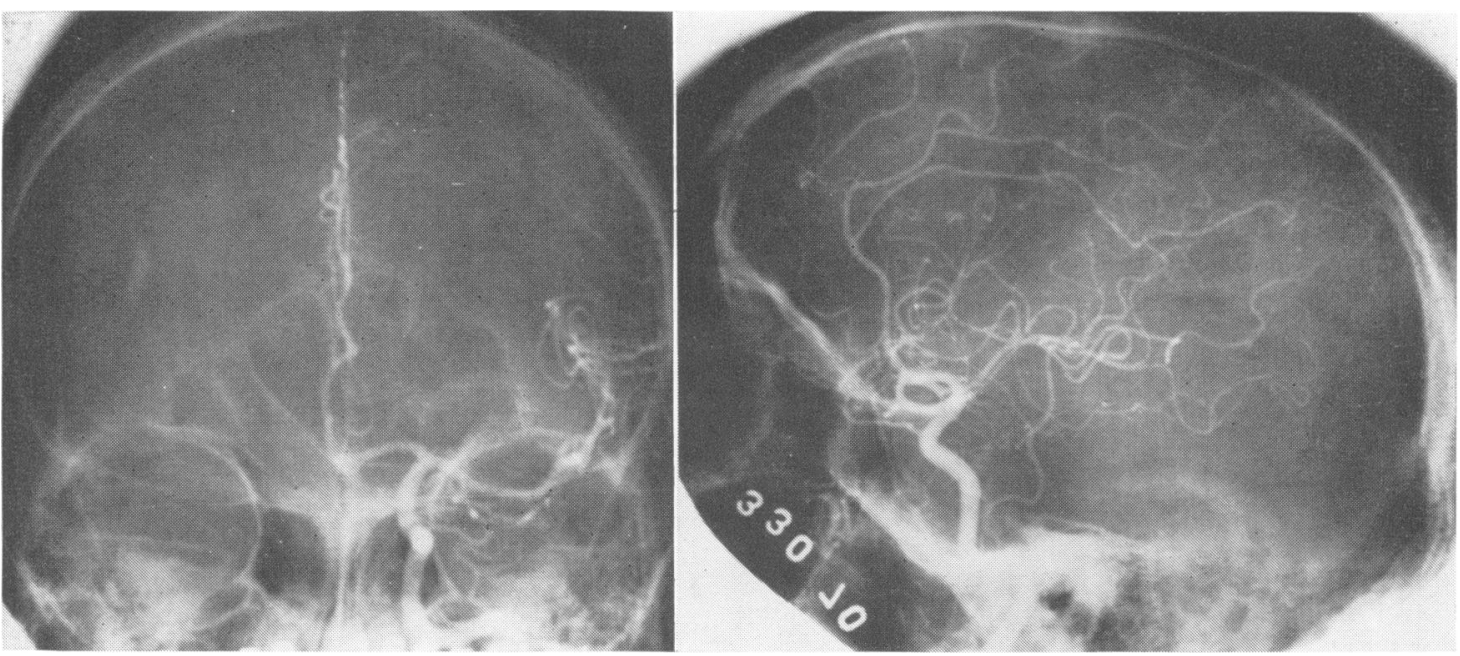

FIG. 4. Case 4 (P.K.) Arteriogram. A-P and lateral views demonstrating presence of hydrocephalus.

Brain scan was normal and a left carotid arteriogram revealed large lateral ventricles. Lumbar puncture demonstrated an opening pressure of $240 \mathrm{~mm}$ of water and the protein was $203 \mathrm{mg} / 100 \mathrm{ml}$. Because she had remained stuporous and the lateral ventricles were large, it was felt that her ventriculostomy and Torkildsen's shunt were not functioning. A ven- triculojugular shunt was performed. She brightened, the hemiplegia improved, and she was able to speak again.

In June 1967 she developed a sudden, recurrent right hemiplegia and aphasia. Left carotid arteriogram demonstrated a complete block of the internal carotid artery. She subsequently developed epilepsy 
but survived until May 1969. Necropsy revealed the floor and dorsum of the sella turcica to be eroded and filled with brownish, semi-liquid necrotic material which did have small areas of viable neoplastic tissue typical of a chromophobe adenoma. The cause of death was bronchopneumonia and a pulmonary embolus.

\section{CASE 2}

P.B., a 73 year old right-handed woman, was admitted to Episcopal Hospital in 1966 with progressive mental obtundity and change of personality over the course of the previous year. Her family reported that she had had progressive unsteadiness of gait for at least two years. In 1959 she had been operated upon at another hospital for a chromophobe adenoma of the pituitary gland and had received postoperative radiation therapy. The patient had a dry, smooth skin, a coarse, raspy voice and she was dull, disoriented, and confused. There was no definite visual field cut, but she was unable to cooperate for a detailed examination. The right optic nerve head appeared pale. She had generalized hyperreflexia and was unable to walk. Radiographs of the skull demonstrated destructive changes of the dorsum sella with deepening of the pituitary fossa and erosion of the floor. Blood PBI was $5 \mu \mathrm{g} / 100 \mathrm{ml}$; urinary excretion of pituitary gonadotropins were less than $12 \mathrm{u}$. in 24 hours; the T-3 index was 23 (normal, 27 to 35). Plasma cortisol was $18 \mu \mathrm{g} / 100 \mathrm{ml}$. in the morning and in the evening 3. Cortisol production was $3.4 \mathrm{mg}$ over 24 hours (normal values 15 to 25). ACTH stimulation test yielded a plasma cortisol content of $12 \mu \mathrm{g} / 100 \mathrm{ml}$. as a baseline and post-stimulation was $27 \mu \mathrm{g} / 100 \mathrm{ml}$. A trial of replacement therapy with hydrocortisone failed to produce a significant improvement. A fractional pneumoencephalogram showed generalized dilatation of the ventricular system (Fig. 2). A ventriculoatrial shunt was performed which almost immediately resulted in a brightening of her mental status. She was discharged on hydrocortisone, $10 \mathrm{mg}$ q.i.d. and thyroid extract, $0 \cdot 12 \mathrm{~g}$ daily. She was able to return to doing her own housework and cooking for two years.

After an acute episode of nausea and vomiting she was again readmitted to the hospital on 17 February 1969. The shunt was performing satisfactorily but it was discovered that she had not been taking her medications. She was again placed on hydrocortisone and thyroid extract and improved to the point where she once again could look after herself.

She subsequently died at home in May 1971 at the age of 78 years, but the circumstance of her death could not be ascertained.
CASE 3

A woman, M.K., was first admitted to the Episcopal Hospital in 1951 because of progressive blurring of vision and headaches. Examination at that time demonstrated a suggestion of right central facial weakness and partial bitemporal hemianopsia with normal visual acuity. She had a markedly expanded pituitary fossa with an eroded floor and barely discernible clinoid processes. The diagnosis of pituitary adenoma was made, and radiotherapy was given, which relieved her headaches. Her vision improved but the patient did not complete the entire projected course of treatment.

In 1960, after recurrence of symptoms, craniotomy was carried out in another hospital. A partially necrotic right temporal lobe was removed together with a large cystic pituitary chromophobe adenoma.

In December 1969 she was readmitted to Episcopal Hospital dehydrated, confused, disoriented, and incontinent. She was blind and both optic discs were very pale. There were no focal neurological signs. Radiography revealed complete destruction of her sella turcica. Plasma PBI was $7 \cdot 7 \mu \mathrm{g} / 100 \mathrm{ml}$., T-4 $2.9 \mu \mathrm{g} / 100 \mathrm{ml}$., and her growth hormone $3 \mathrm{ng} / 100 \mathrm{mb}$ Cortisol production was $12 \mathrm{mg} / 24$ hours. Plasm\$ cortisol content in the morning and before ACTH stimulation was $3 \cdot 1 \mu \mathrm{g} / 100 \mathrm{ml}$; after ACTH stimulation it was 29. A pneumoencephalogram utilizing a limited amount of air $(25 \mathrm{ml}$.) demonstrate a huge pituitary tumour with widespread suprasellas extension, particularly encroaching upon the inferio portions of the third ventricle up to the foramen of Monro (Fig. 3). The lateral ventricles were grossly dilated. She was prepared with intravenous hydrocortisone and a ventriculojugular shunt performed She became oriented and continent within 48 hours Two weeks later a left transfrontal craniotomy was performed with almost total removal of a huge chromophobe adenoma. She awoke after surgery and appeared to be in good condition for 48 hours, but then developed a series of generalized grand mal seizures. Despite reasonably prompt control with anticonvulsant medications, she remained stuporous. She improved slowly but never became competent She died in November 1970 at the age of 66 years.

\section{CASE 4}

P.K., a 45 year old man, was admitted to Episcopal Hospital in March 1970, with a four month history of progressive mental and personality deterioration. The family had noted that the patient had difficulty with vision but details were lacking. During the same period he had progressive difficulty with his gait. The patient was conscious, but dull and disoriented. Funduscopic examination revealed pallor of both 
optic discs, and a bitemporal hemianopsia was present. Visual acuity could not be determined. The sella turcica was enlarged with erosion of the floor and infralateral wall of the optic foramina on the left. His pituitary and thyroid functions were normal. Arteriography demonstrated a pituitary tumour with hydrocephalus (Fig. 4). He was placed on $100 \mathrm{mg}$ hydrocortisone daily and a ventriculojugular shunt was performed on 31 March 1970. On cannulization of the lateral ventricles, the hydrocephalus was confirmed. After the shunting procedure, he was definitely brighter and more oriented. He was continued on hydrocortisone. On 2 April 1970 a large chromophobe adenoma of the pituitary gland was removed in toto. Postoperatively, the patient did well and, though he was fully alert after the first few days, he remained disoriented for time and place and occasionally for person. He was discharged on $30 \mathrm{mg}$ hydrocortisone and $200 \mathrm{mg}$ phenytoin daily. In May 1970, he had fully recovered intellectually and the valve was functioning well. By December 1970 his visual acuity could be corrected on the left to $20 / 20$ but not beyond 20/200 on the right. He had returned to operating a service station. When last seen in March 1972 he was continuing to do well, on substitution endocrine therapy and his valve was functioning.

\section{DISCUSSION}

So-called occult or normal pressure hydrocephalus in the adult generally presents as a disturbance of gait and mentation. Apathy, irritability, incontinence, and severe disorientation can develop in these patients. Hypopituitarism frequently produces similar changes and therefore in the presence of a known tumour of the pituitary gland it is difficult, if not impossible, to differentiate between these two possible complications on a clinical basis alone. The initial opinion on cases 1-3 was that their clinical picture was the result of an endocrine aberration. They had previously been operated upon for pituitary tumour and given radiation therapy postoperatively. All three were given endocrine replacement therapy and only when there was no significant improvement was hydrocephalus considered as the cause of the clinical picture. Treatment of the latter by shunting produced prompt if not always complete improvement. Patient P.B. (case 2) was able to go home and do her own cooking and housework and generally look after herself; patient J.K. (case 1) brightened to the point where she could walk and talk but required nursing home assistance. M.K. (case 3) became oriented and continent after shunting; however, after subsequent surgery on her pituitary gland she had a series of postoperative convulsions and became deeply stuporous. She never fully recovered and was confined to bed in a nursing home for one year before she died. The improvement in each case was reasonably prompt and not dependent upon change in endocrine substitution therapy. In one patient, P.B. (case 2), hypopituitarism and hydrocephalus were both clearly present, and while some improvement occurred with replacement therapy her improvement was dramatic only after her hydrocephalus had been shunted. We were fully alerted to this problem when the last patient (P.K.) was encountered and, on the basis of the arteriogram, proceeded with shunting immediately. It can be speculated that, if shunting had been resorted to sooner in the first three patients, the improvement might have been more complete.

There are several mechanisms involved in production of hydrocephalus with pituitary tumours (Taveras and Wood, 1964; Schmitz et al., 1967). Approximately $25 \%$ of all pituitary adenomas, and the majority of large adenomas, grow upward and forward, producing a deformity of the inferior aspect of the anterior horns of lateral ventricles. These tumours rarely become large enough to cause an obstruction at the foramen of Monro. The principal directional growth in the other cases is upward and backward. In these instances the tumour may invade the suprasellar area at an early stage and large tumours may also invaginate the floor of the third ventricle and cause an obstruction of the aqueduct of Sylvius. A third possibility is that the cisterna chiasmatica and cisterna interpeduncularis can be encroached upon sufficiently or even obliterated and in this manner produce a hydrocephalus. In this series, three of the tumours had become large enough to involve the third ventricle. In the other case there was no evidence of suprasellar extension of the tumour. As three of the four cases had been previously operated upon and irradiated, scarring from surgery and irradiation obliterating the cisterna must also be considered as a possible contributory factor. The process in all instances was obviously slow enough to permit adjustments to occur, 
thereby avoiding any obvious increase in intracranial pressure accompanying the hydrocephalus.

This series of patients identified another cause of occult hydrocephalus. It further emphasizes the desirability of using cerebral contrast media studies in the evaluation of patients with suspected or proven pituitary tumours either before definitive treatment or in those patients whose progress after treatment is poor. Indeed, arteriography before surgery on a suspected pituitary tumour has been generally recommended to exclude an aneurysm. If patients are judged to be suffering from hypopituitarism and their response to substitution therapy is not complete, it is necessary to exclude hydrocephalus also. Patient P.K. presents the unusual picture of hydrocephalus complicating the presenting clinical picture of pituitary adenoma. The relief of the former by shunting permitted a technically less complicated surgical attack on the latter, with an exceptionally fine end result.

\section{REFERENCES}

Dandy, W. E. (1969). The Brain. Harper and Row: New York. Davidoff, L. M., and Epstein, B. S. (1955). The Abnormal Pneumoencephalogram. Lea and Febiger: Philadelphia.

Pancoast, H. K., Pendergrass, E. P., and Schaeffer, J. P. (1940). The Head and Neck in Roentgen Diagnosis. Thomas: Springfield, Ill.

Schmitz, A. L., Haveson, S. B., and Hanna, D. (1967). Illustrative Cranial Neuroradiology. Thomas: Springfield, III.

Stern, W. E., and Batzdorf, U. (1970). Intracranial removal of pituitary adenomas. Journal of Neurosurgery, 33, 564-573.

Taveras, J. M., and Wood, E. H. (1964). Diagnostic Neuroradiology. William and Wilkins: Baltimore. 